\title{
AC 2007-273: CAN LEAN MANUFACTURING BE APPLIED TO UNIVERSITY LABORATORIES?
}

\section{Shirish Sreedharan , University of Missouri}

\section{Frank Liou, University of Missouri}

Frank Liou is a Professor in the Mechanical Engineering Department at the University of Missouri-Rolla (UMR). He currently serves as the Director of the Manufacturing Engineering Program at UMR. His teaching and research interests include CAD/CAM, rapid prototyping, and rapid manufacturing. He has published over 100 technical papers and has research grants and contracts over $\$ 8 \mathrm{M}$. 


\title{
Can Lean Manufacturing Be Applied to University Laboratories?
}

\author{
Shirish Sreedharan and Frank Liou \\ University of Missouri-Rolla
}

\begin{abstract}
Lean manufacturing focuses on eliminating waste and improving flow using techniques such as value stream mapping, standard work, $5 \mathrm{~S}$, single minute exchange of dies, and visual management. This paper presents a case study to show the value of creating and facilitating student learning in lean manufacturing in the university environment. This case study implemented lean manufacturing principles to a university rapid manufacturing laboratory. The approach begins with the application of value stream mapping to identify gaps between the current and future state maps. Lean techniques were then implemented to achieve the future state map. These projects have facilitated experiential learning through "Hear, See, and Do" cycle by bridging the gap between academia and industry via learning modules in lean manufacturing education. It not only benefits students working on the lean project as a practical learning experience, but also acts as a lean manufacturing education show case to students on campus.
\end{abstract}

\section{Introduction}

Lean manufacturing principles represent a radical departure from traditional plant techniques [1]. The employee's roles, skill-sets, process-requirements, and rules have changed. Team members must operate like an independent business with total responsibility for the quality, manufacturing and delivery of the product to their customers. Team members need to be empowered with current information, dedicated resources, and established boundaries to accomplish their mission. Some literatures have shown the benefits of applying lean principles to non-traditional environment, such as offices [2-4], and laboratories [5]. Lean office techniques can be implemented to build high performance organizations, and people, processes and tools of an organization - and then maximize that value by optimizing the flow of information and ideas. Laboratories have been slow to adopt lean manufacturing principles to help improve their performance and the services they provide to their customers [6]. Some questions, such as,

- What would be the impact of using the lean manufacturing principles into a university laboratory?

- How would this change the laboratory and the students working there?

- Would this project provide a learning environment in lean manufacturing?

This paper is to report this experience. The implementation of lean manufacturing principles to the Laser Aided Manufacturing Processes (LAMP) Lab at the University of Missouri-Rolla was used as a case study. This lab is a good example as it has been used for several years, there are many groups of students working on it, and it is pretty busy and has an agenda, similar to an industrial setting.

LAMP Laboratory combines laser deposition and machining processes to develop a hybrid rapid manufacturing process to build functional metal parts. The configuration of

"Proceedings of the 2007 American Society for Engineering Education Annual Conference \& Exposition Copyright (C) 2007, American Society for Engineering Education” 
this hybrid system includes a metal deposition system mounted on a multi-axis CNC machine. With the addition of extra rotations, the support structures may not be necessary for the deposition process in order to build a complicated shape. This process uses laser deposition for material deposition and CNC milling for material removal. It includes two major systems: a laser deposition system (Rofin-Sinar 025) and a CNC milling machine system (Fadal VMC-3016L). The laser deposition system and CNC milling machine work in shifts in a five-axis motion mode. The laser deposition system consists of a laser and a powder feeder. Due to the high power laser operation, the safety issue is very critical to the laboratory.

Overall, LAMP lab is comprised of a central chamber that houses the CNC machine and laser input, a powder feeder, a PC setup for executing machining codes, gas outlets, and diode laser. The layout of the lab is as shown in Figure 1. The lab is primarily used by the students for conducting research experiments. Some snap shots of the lab settings are shown in Figures 2-3. It can be seen that some help is needed to get the lab more organized.

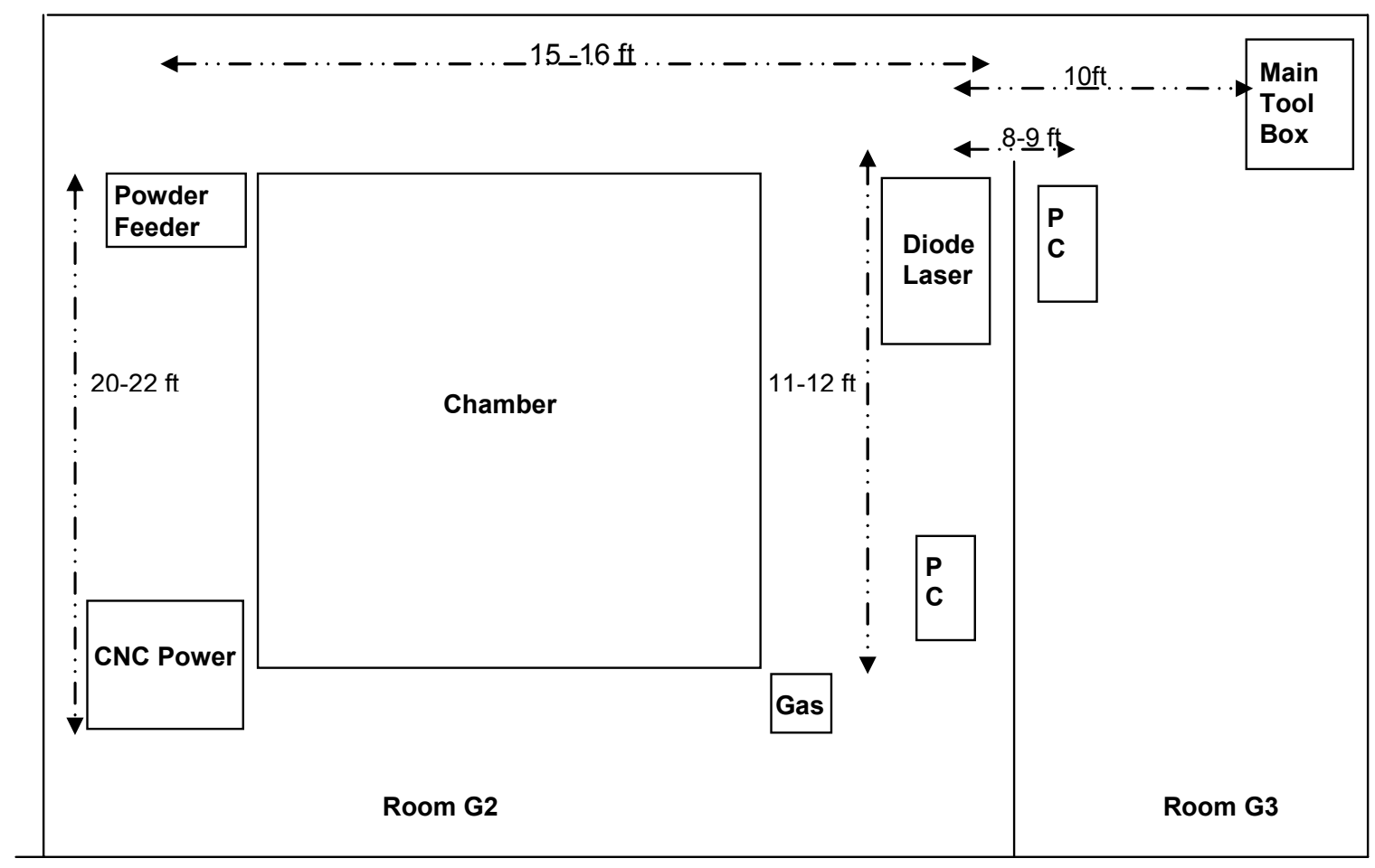

Figure 1 LAMP Lab Floor Layout 


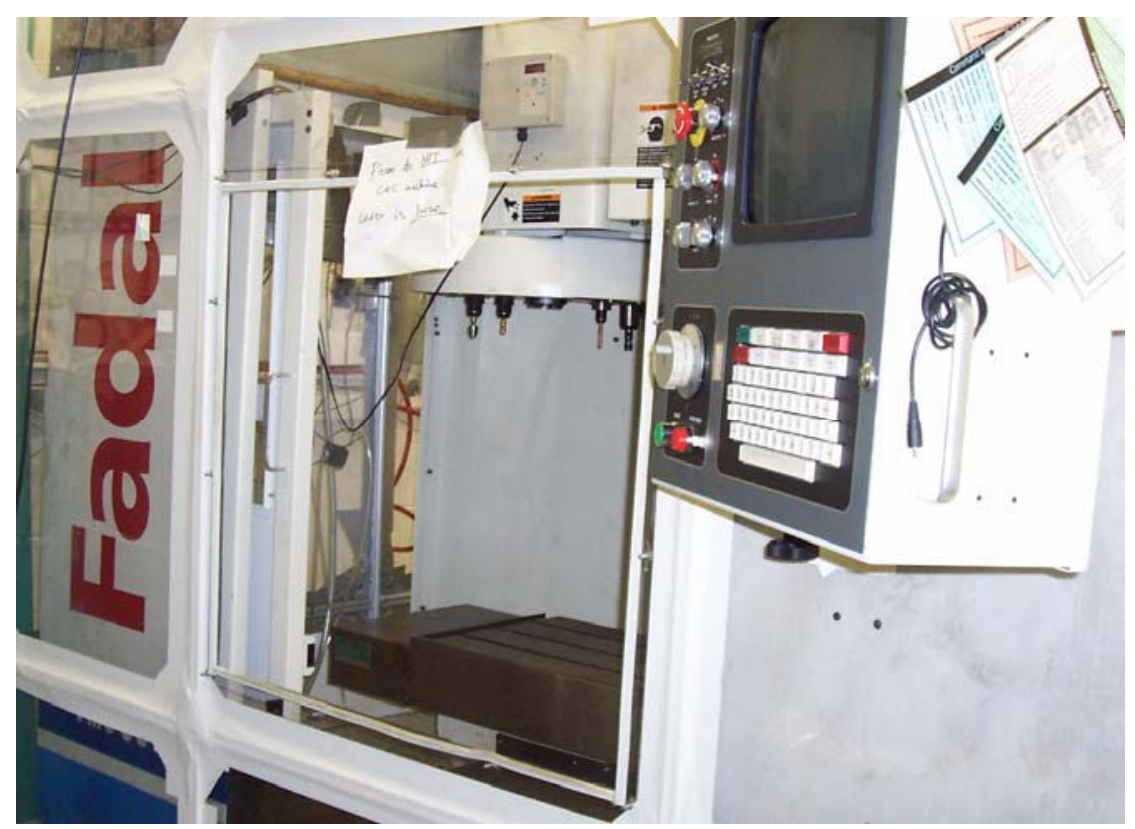

Figure 2. CNC machine in the LAMP lab.

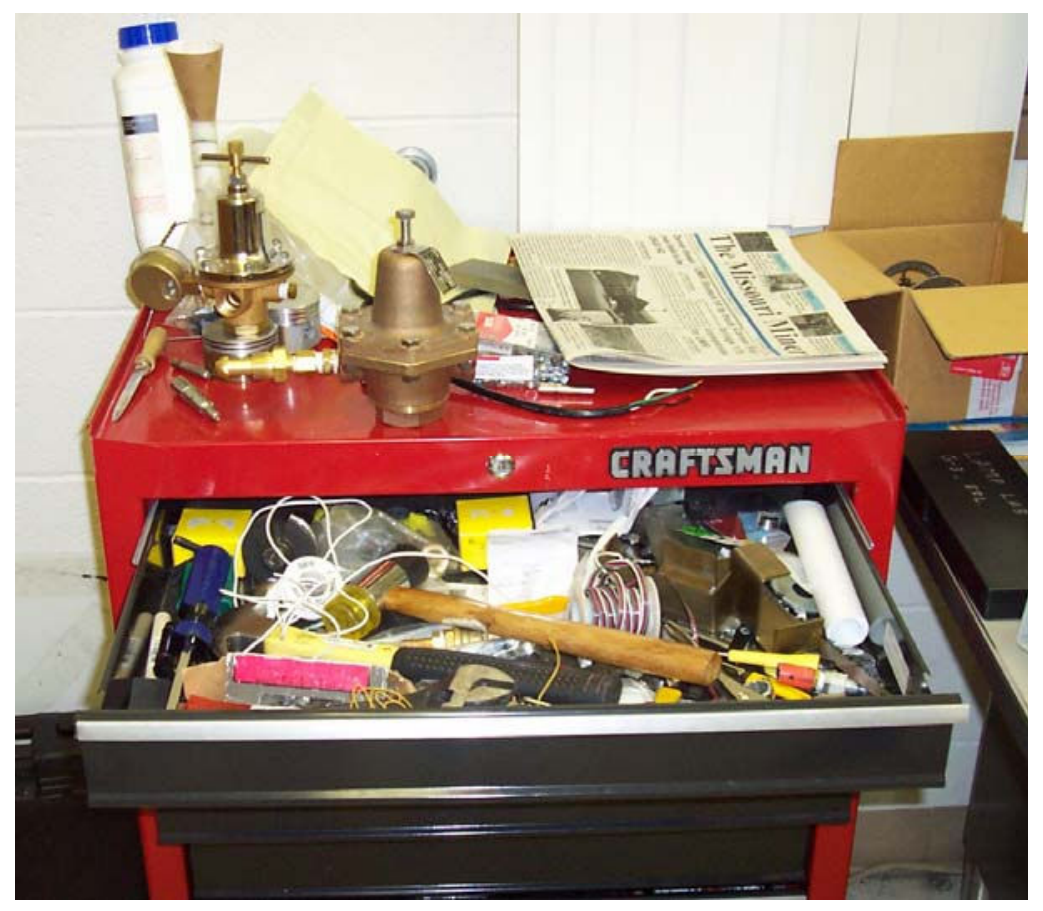

Figure 3. A snapshot at the tool box.

\section{Value Stream Mapping}

Value stream mapping is a lean tool that is used to identify all the value added and nonvalue added activities that are required to bring a product from raw material state to the hands of the customer. So, by following a products production path from beginning to

"Proceedings of the 2007 American Society for Engineering Education Annual Conference \& Exposition Copyright (C) 2007, American Society for Engineering Education” 
end, and by drawing a visual representation of every process, as in both the flow of material and information, we can generate a value stream map. Using this above technique, a current state map of the LAMP lab was charted and a future state map was proposed identifying improvement targets for the lab. A shop floor layout with recommendations for floor rearrangement is also provided.

\section{What is $5 \mathrm{~S}$ ?}

Based on Japanese words that begin with ' $\mathrm{S}$ ', the 5S Philosophy focuses on effective work place organization and standardized work procedures. $5 \mathrm{~S}$ simplifies your work environment, reduces waste and non-value activity while improving quality efficiency and safety.

\section{Japanese words}

- Seiri - Sort (Housekeeping)

- Seiton - Set in Order (Workplace Organization)

- Seison - Shine (Cleanup)

- Seiketsu - Standardize (Keep Cleanliness)

- Shitsuke - Sustain (Discipline)

Benefits of $5 \mathrm{~S}$ for lab users

- A more pleasant work environment

- More satisfying jobs

- Makes your job easier

- A process that makes sense

- Pride in the workplace

- Associates and customer respect

- Positive mental attitude

Once fully implemented, the $5 \mathrm{~S}$ process can increase morale, create positive impressions on customers, and increase efficiency and organization. Not only will employees feel better about where they work, the effect on continuous improvement can lead to less waste, better quality and faster lead times. Any of which will make your organization more profitable and competitive in the market place. Ultimately, $5 \mathrm{~S}$ creates a better place to work.

\section{Project Objective}

The goal of this research project was to apply lean manufacturing techniques achieve flow in the LAMP lab. The objectives of this project are:

- To develop current state map,

- Propose a future state map, and

- $\quad$ To achieve $2 \mathrm{~S}$.

\section{Solution Approach}

- Kick-off presentation

- Map Current state VSM with a student volunteer

"Proceedings of the 2007 American Society for Engineering Education Annual Conference \& Exposition Copyright (C) 2007, American Society for Engineering Education” 
- $1 \mathrm{~S}$

- Red tagging

- Identify kaizen blitz activities

- Develop future VSM

- $2 \mathrm{~S}$

- Apply visual controls

A kick off presentation was done to inform users of the lab facility of future changes and the respective roles users will have to play in getting through the $5 \mathrm{~S}$ 's. The data collection for the VSM was achieved by walking through an experimental procedure executed by the students.

\section{Current State Map}

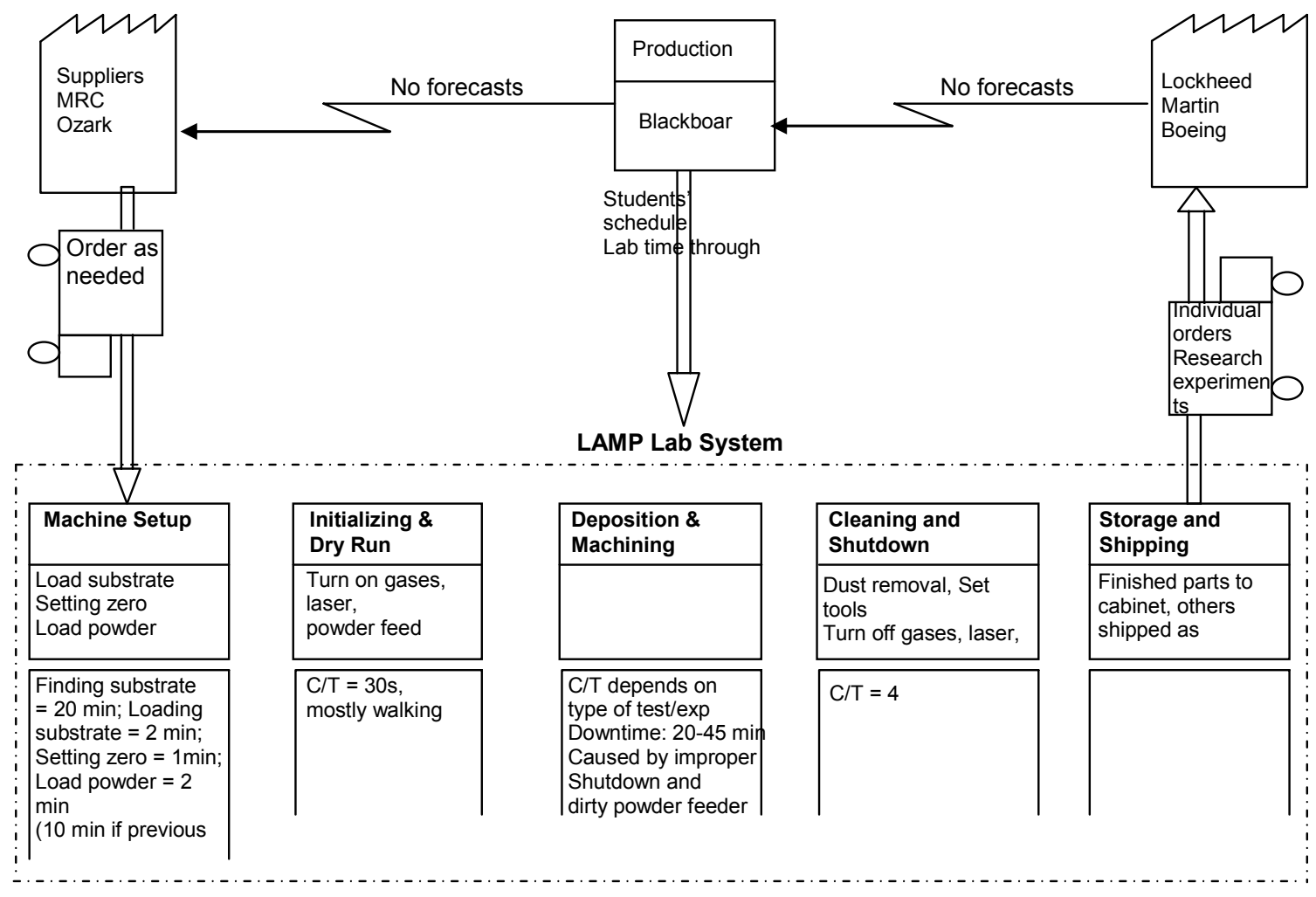

Figure 2 Current state value stream map

The current state map shown above captures the lab system as it is. It shows the flow of information (right to left) and the flow operations (left to right). Being an experimental laboratory the activities that constitute a typical experimental setup are grouped and tagged under various process boxes. Since each experiment is unique, it is difficult to 
tabulate an overall lead time in for executing a particular experiment. The time consumed for various activities that constitute a process have been captured here.

\section{The First S: Sort}

The following are the key steps in achieve the first $S$ :

- Separate needed from unneeded items

- Leave only the bare essentials

1. Remove unneeded items from the work area (red tag)

2. Remove all excess items from the work area

3 . Is it needed, in what quantities, and where should it be located?

- Hold excess items within the shop storage area for 14 days or less

- Assign a person to organize and manage the shop storage area

- Assign a person to organize and manage the consolidated storage area

- Organize working / storage area, disposing of all items in red tag area in a predetermined time

\section{Red Tag System}

- Start the Red Tag Process within a designated area (shop, storage area, warehouse, etc.)

- Identify the Red Tag targets

- Set Red Tag criteria (based on value addition to the lab environment)

- Make Red Tags

- Attach Red Tags

- Evaluate Red Tag Items

- Document the results of the Red Tagged Items

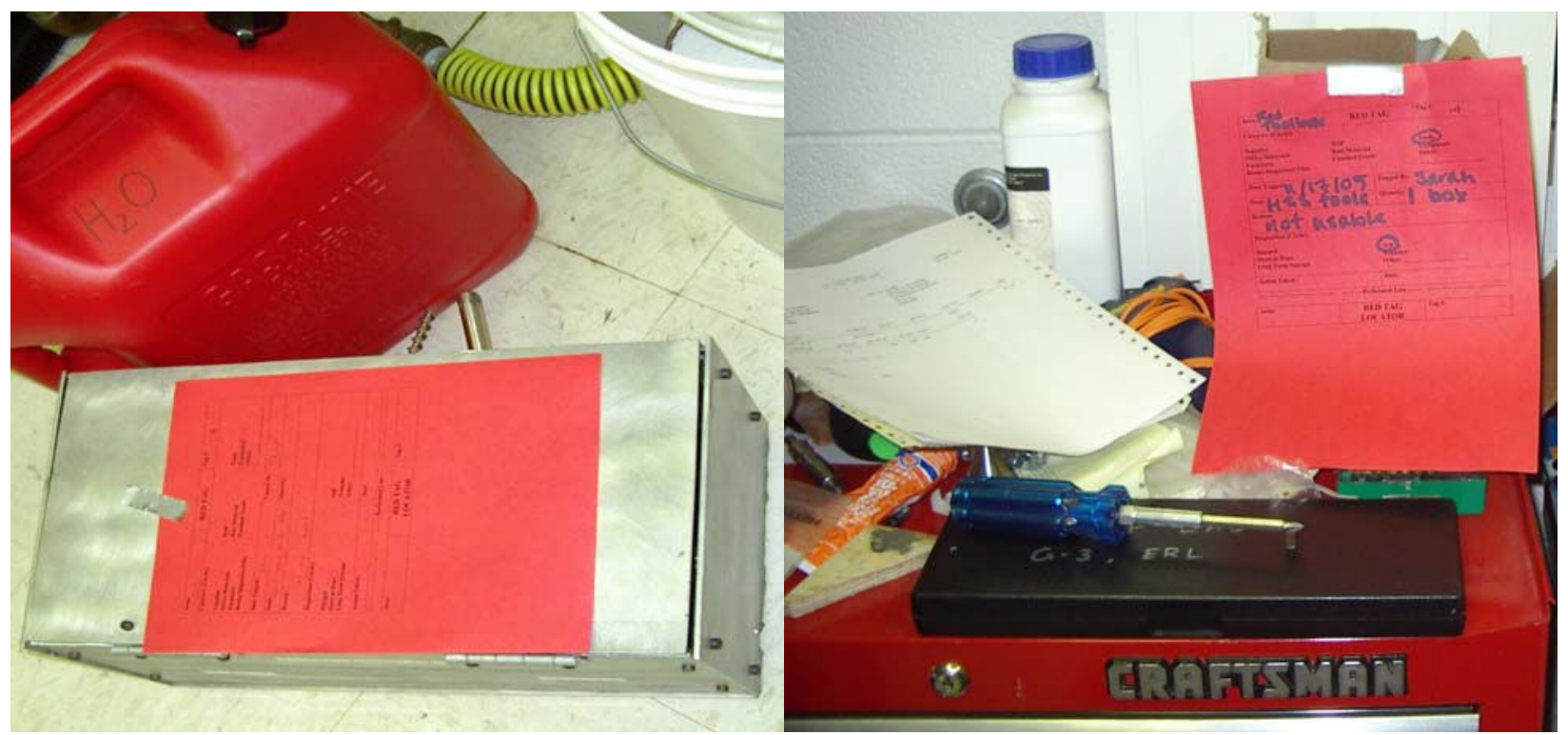

Figure 3 Red tag labels attached to items 


\section{Proposed Future State Map}

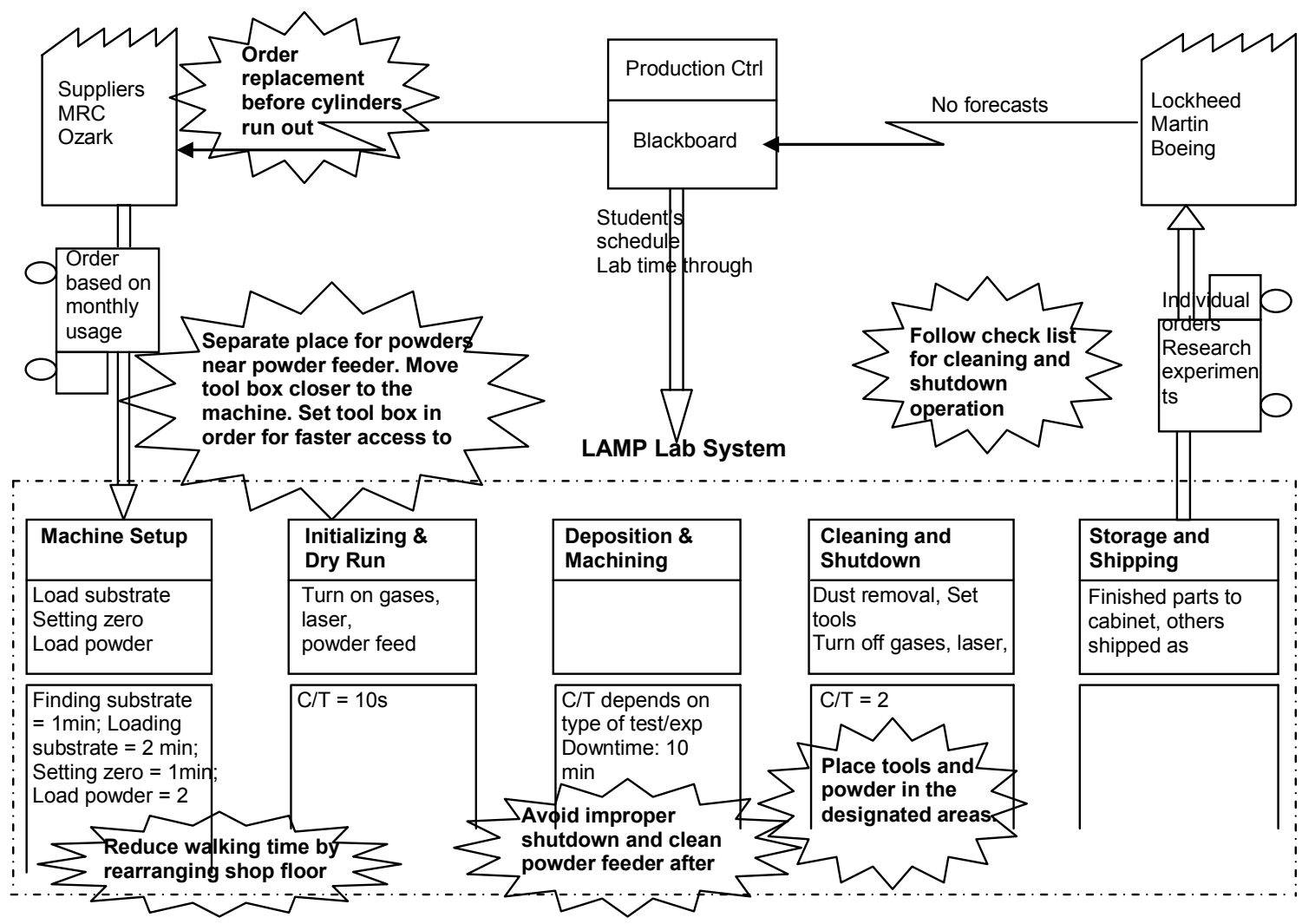

Figure 4 Future state value stream map

The future state map is as shown above. The map shows the kaizan blitz events that were arrived at after analyzing the current state map for possible improvements. It is estimated that with the improvements in place there will be a reduction in the time taken to complete a typical experiment. The figure below shows the main tool box that is now closer to the lab system and the designated shelf for the powders.

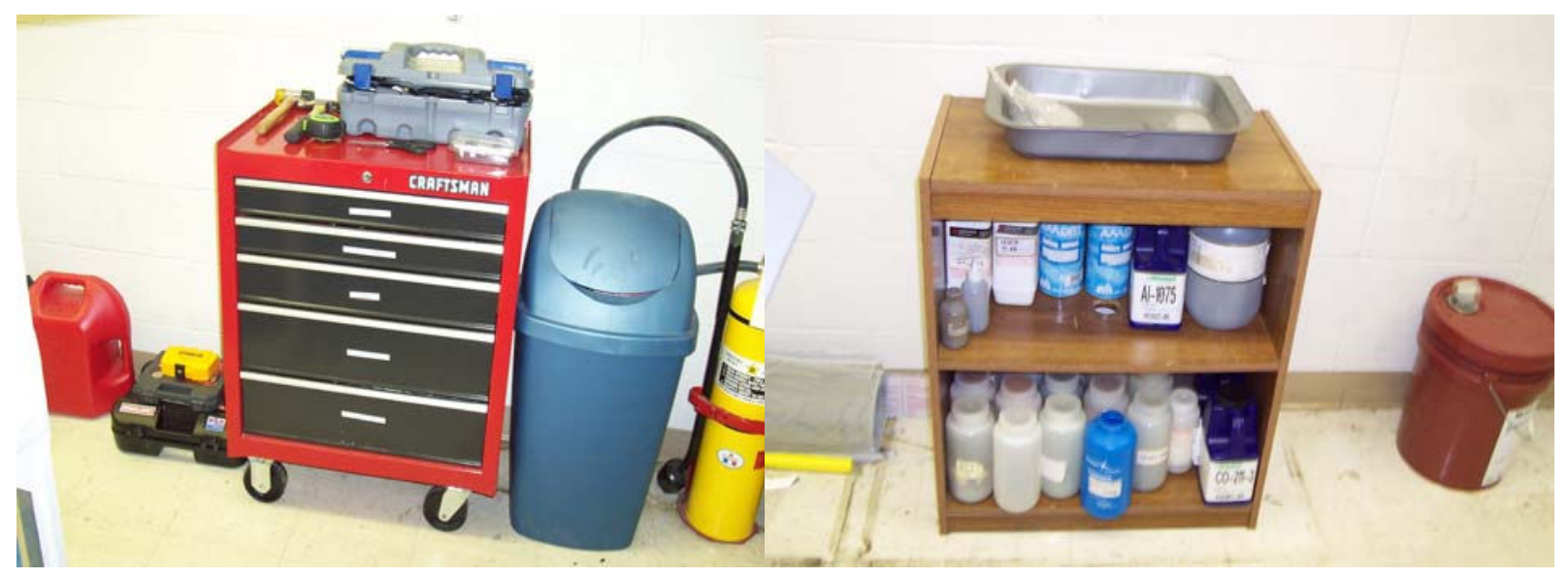

Figure 5 Rearranged tool box and the designated powder shelf

"Proceedings of the 2007 American Society for Engineering Education Annual Conference \& Exposition Copyright (C) 2007, American Society for Engineering Education" 
It is also suggested that the users follow a check list for completing cleaning and shutdown operations. A check list for this action was designed shown in Figure 6.

Checklist for Cleaning and Shutdown Operations

\section{Attention students who make use of the LAMP Lab!}

Please make sure you have completed the following check list for proper cleaning and shutdown operations. This will ensure clean and efficient work environment for all users. Thank you for your cooperation!

- Remove your work piece from the machine.

- Making use of the vacuum cleaner, vacuum the chamber to remove dust.

- Manual wipe down all other areas for dust.

- Be sure to turn off the laser.

- Be sure to turn off the powder feeder.

- Be sure to turn of the gas cylinders.

- Clean the powder feeder system

- If there is only a quarter of gas left in the cylinder when you shutdown, please inform $X X X$ and order a replacement.

- Make sure powder bottles are placed back in the designated area

- Make sure to replace the tools in the main tool box.

Figure 6 Check list

The lab users are expected to follow through this check list after they have used the facility, so that the next lab user is given a clean and orderly work place. 


\section{Proposed Future Shop Floor Layout}

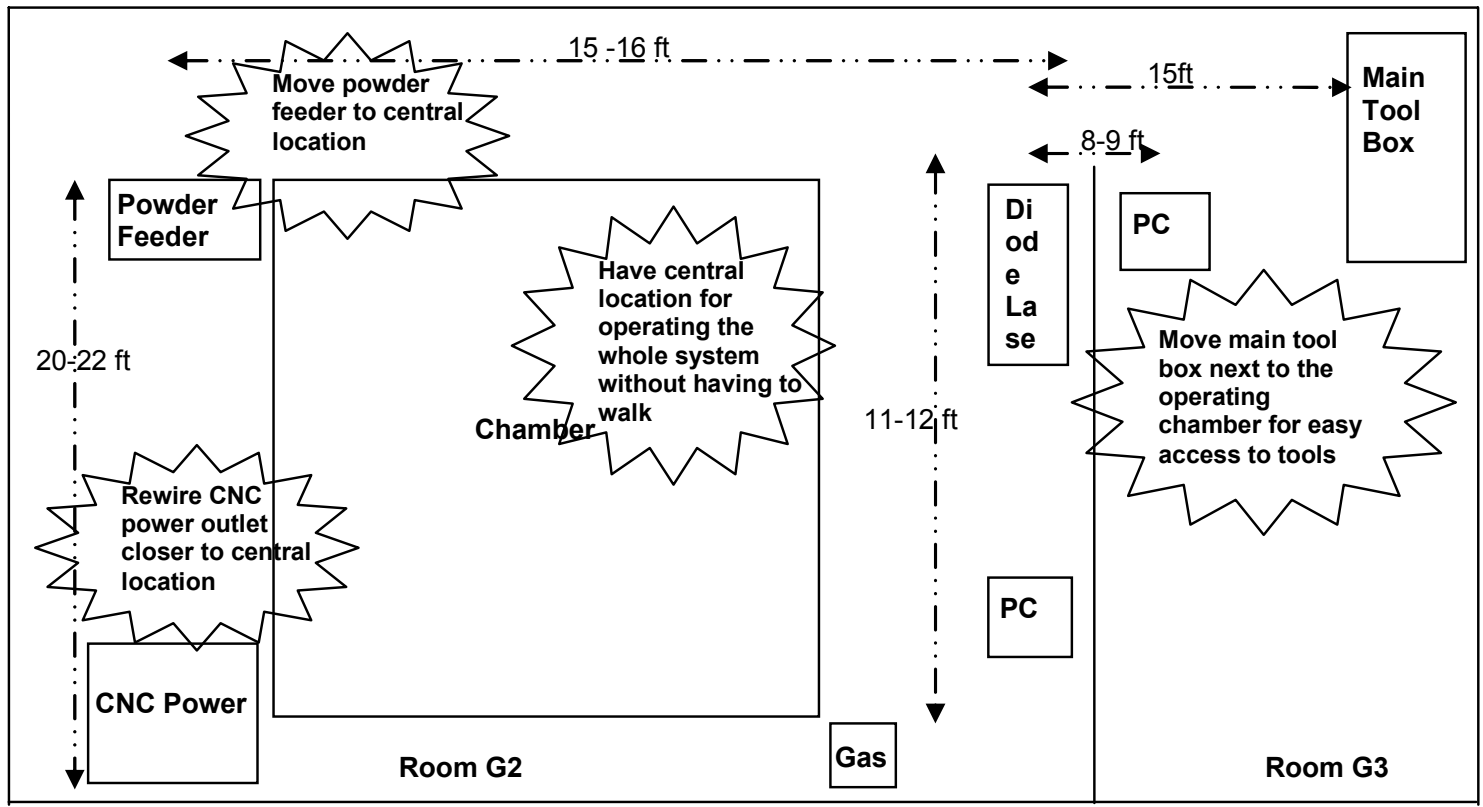

Figure 7 Future floor layout with blitz events

The proposed future shop floor layout focuses on having a central location for operating the whole lab system with out having to walk. The expectation is to have a more ergonomic work place where the user can accomplish more from the central location through minimal walking time. To achieve this, it is proposed that the powder feeder and main tool box be moved closer to the right of the chamber where the users spends most about time. It is also proposed to rewire the $\mathrm{CNC}$ power outlet so that the user does not have to walk across the room at the start of the experiment.

\section{The Second S: Set in order}

The objectives for the second $\mathrm{S}$ are to:

- Arrange needed items so they can be easily retrieved, used, and put away

- Get rid of waste in production and production support activities

- Use First-in first-out (FIFO)

- Save space and time

There are some basic guidelines for setting in order. They are:

- A place for everything and everything in its place

- Place parts, tools, and instructional manuals close to the point of use for "motion improvement"

- Store similar items together on the same row

- Different items in different rows

- Color code for quickly identifying items

- Clearly label each item and its storage area

"Proceedings of the 2007 American Society for Engineering Education Annual Conference \& Exposition Copyright (C) 2007, American Society for Engineering Education” 
- Use specially designed carts to organize tools, fixtures, jigs, and measuring devices that are needed for each machine, color coded for each job.

As students working in the lab are often tied after the work, some visual control tools, some examples as shown in Figure 8, were used to remind users of the need to maintain a lean and efficient work area.

\begin{tabular}{|c|}
\hline Attention!!! \\
Please put back \\
powder bottles to the \\
designated areas after \\
use. Thank you! \\
Dr. Frank Liou \\
Director LAMP Lab
\end{tabular}

\begin{tabular}{|c|}
\hline Attention!!! \\
Please replace tools to \\
the main tool box. \\
Please do not misplace \\
the tools. Thank you! \\
Dr. Frank Liou \\
Director LAMP Lab
\end{tabular}

Figure 8. Some examples of visual control signs designed and used in the lab.

Based on the above guidelines, a basic level of $2 \mathrm{~S}$ was achieved. The results showing the before and after implementation are shown below.

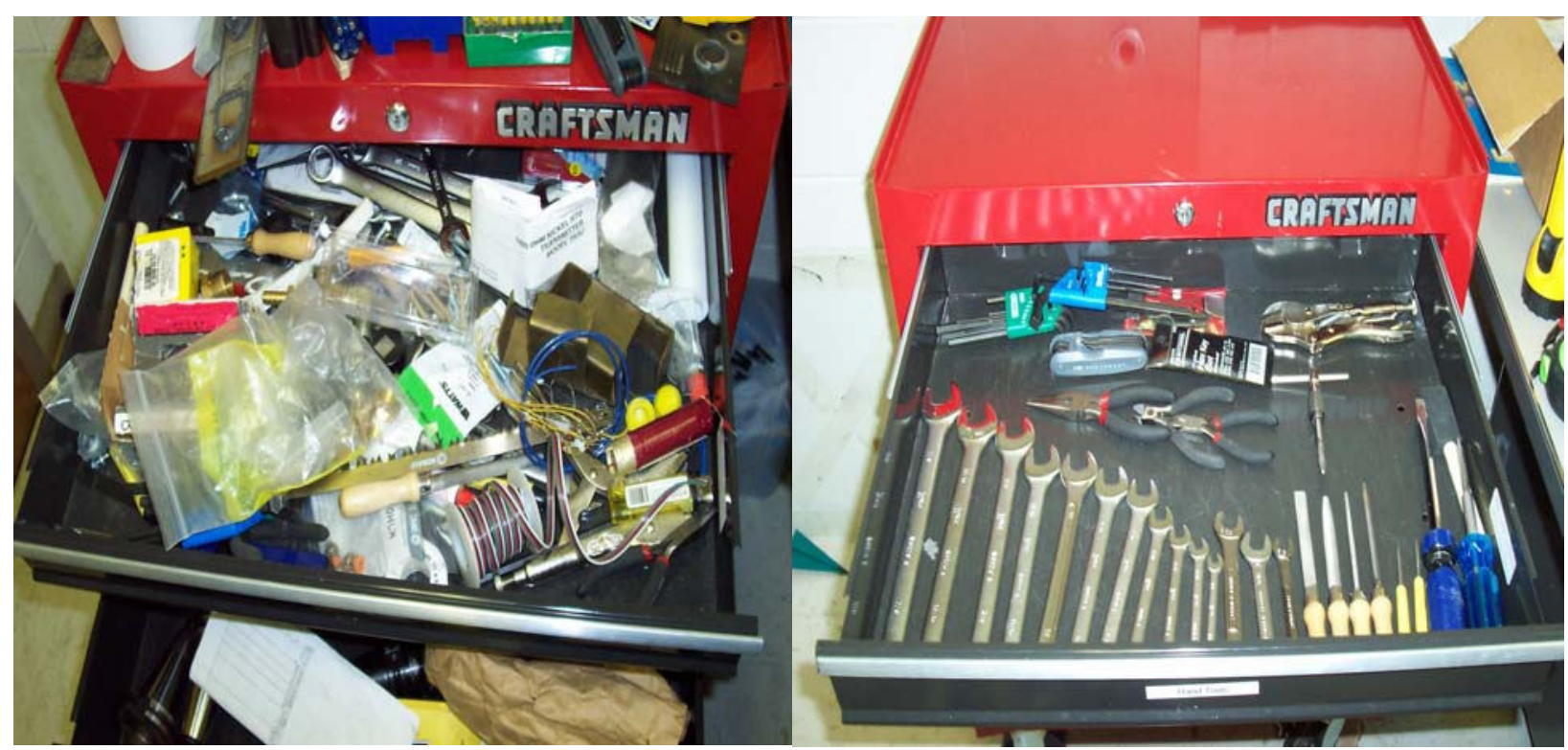

Figure 8 Main Tool Box: Before (left) and After (right) 


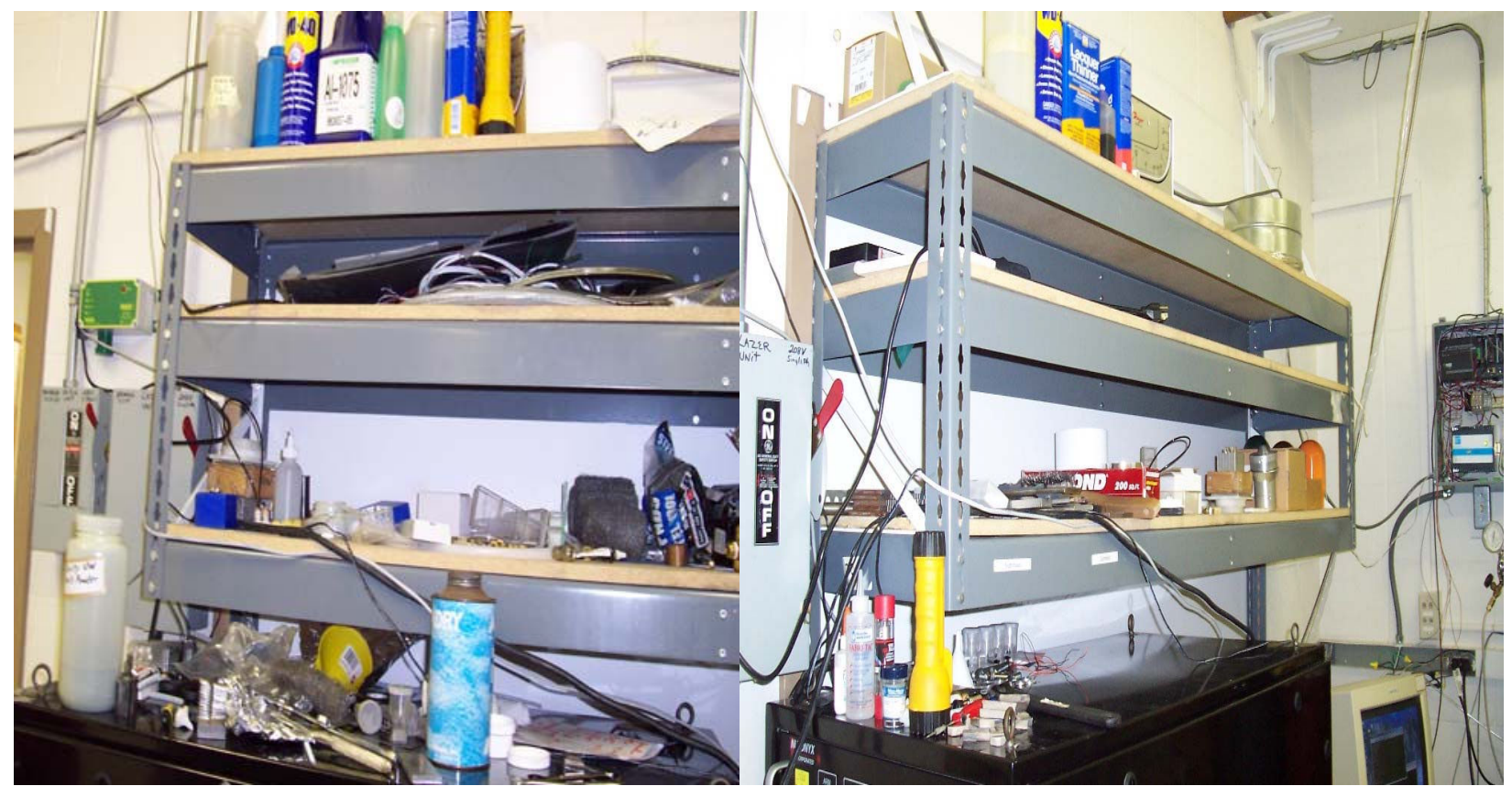

Figure 9 Shelf Storage: Before (left) and After (right)

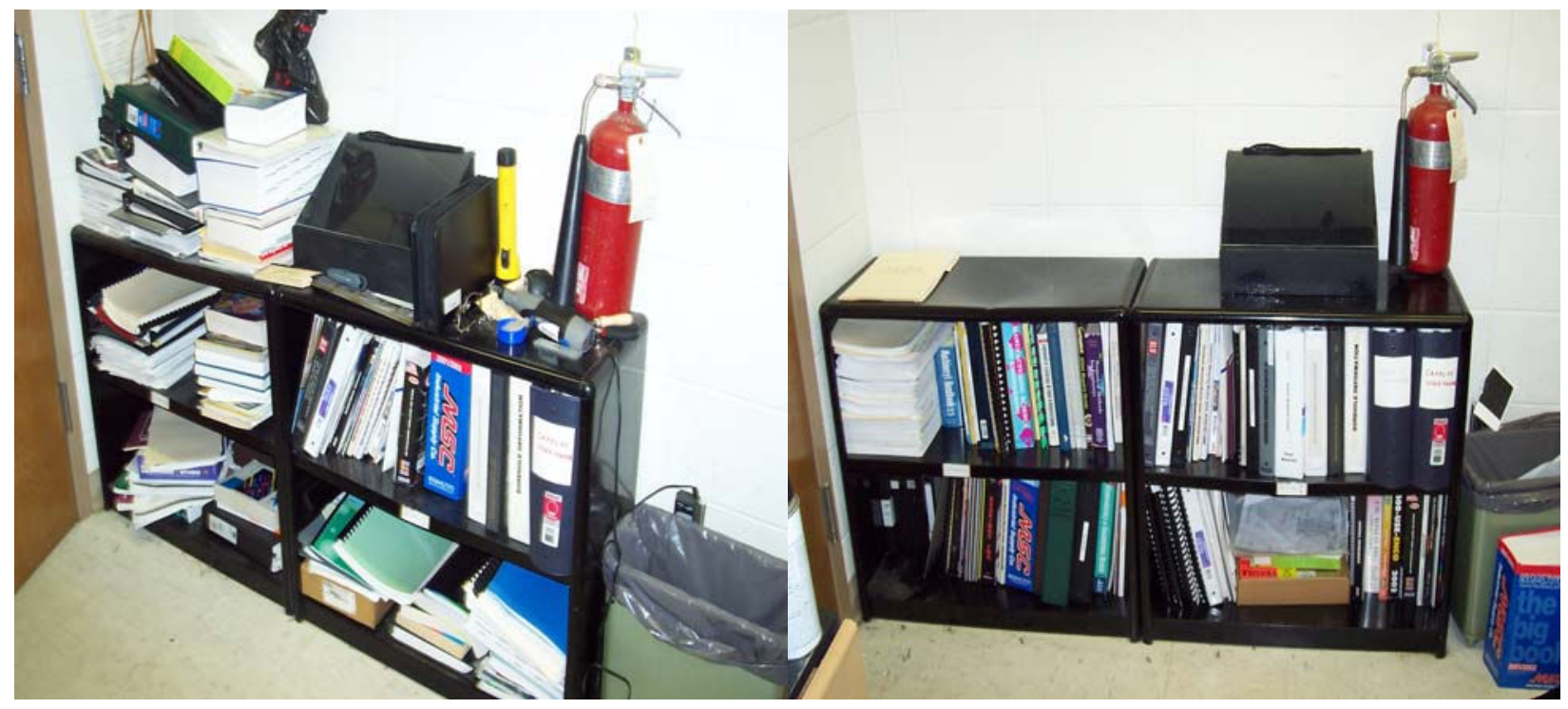

Figure 10 Shelf for manuals, literature review and catalogs: Before (left) and After (right) 


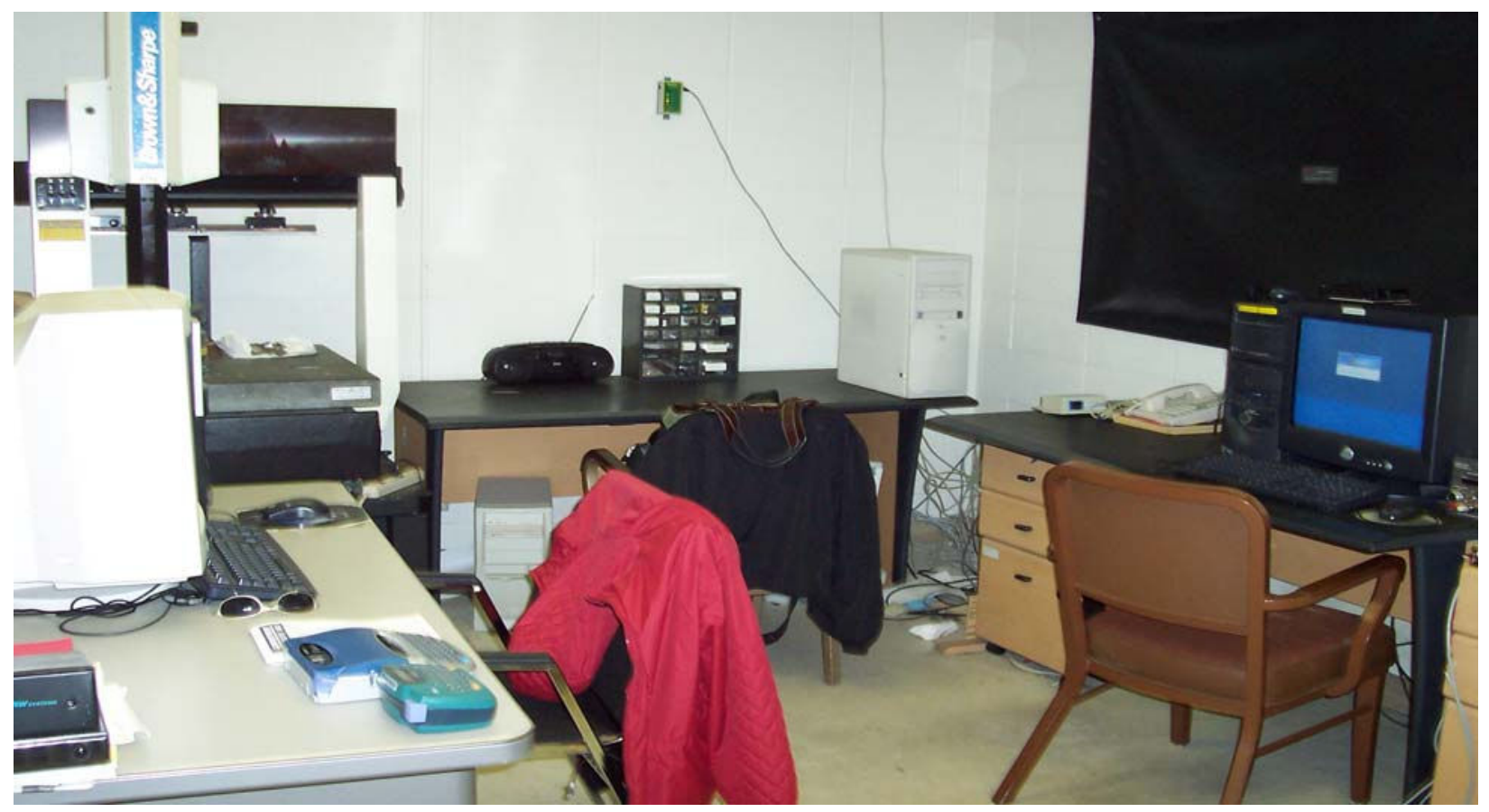

Figure 11 Student office area after initial $2 \mathrm{~S}$

\section{Conclusion}

At this point, a basic level of $2 \mathrm{~S}$ has been achieved and the improvements that have been achieved will contribute to achieving flow in the lab system. It can see the immediate impact of the lean manufacturing on the laboratory setting, and created a much more efficient environment. But in order for the system to stabilize it is important to move forward and achieve the remaining three S's. The key to achieving stability and sustaining these improvements is to have internal audits on a monthly basis. Visual control tools can also play an important role in reminding users of the need to maintain a lean and efficient work area. Although not yet fully implemented, the proposed future shop floor layout if achieved will create an ergonomic work area. Application of lean techniques in a lab environment presents a challenge because of the stand alone machine setup and individualist nature of each lab experiment. This project was an attempt in the application of lean techniques in an unconventional setting. It has a good impact to students as they can see the results on campus.

The 2S (Shine, Standardize) has been implemented. However, in the university laboratory environment, the shuffling of students is pretty frequent and thus creating another challenge: to sustain and requires good discipline. Table 1 and Table 2 show the average responses and comments of the students working in the LAMP lab. In general the students noticed good differences before and after implementing lean in the lab. However, after certain time (6 months), the rules were not enforced, and thus it started to go back to the previous condition. We feel that sustaining the activities is perhaps the toughest of the tasks. We are currently working on the associated subtasks in the sustain phase, such as allocating dedicated schedule and duties for each lab user, offering 
rewards and recognition for individuals doing well, and retraining new students to sustain the laboratory conditions.

\begin{tabular}{|l|c|}
\hline Questions & $\begin{array}{l}\text { Average responded points out of 4, } \\
\text { with 4 being the "a lot difference" } \\
\text { and 1 being "not at all" }\end{array}$ \\
\hline $\begin{array}{l}\text { Did you see a difference before and after } \\
\text { implementing lean in the lab? }\end{array}$ & 3.5 \\
\hline $\begin{array}{l}\text { Did you see a difference before and 3 months } \\
\text { after implementing lean in the lab? }\end{array}$ & 3.4 \\
\hline $\begin{array}{l}\text { Did you see a difference before and 6 months } \\
\text { after implementing lean in the lab? }\end{array}$ & 2.3 \\
\hline $\begin{array}{l}\text { Do you think it worth implementing lean in the } \\
\text { lab? }\end{array}$ & 3.3 \\
\hline $\begin{array}{l}\text { Did you learn "lean" after implementing lean in } \\
\text { the lab? }\end{array}$ & 3.4 \\
\hline
\end{tabular}

Table 1. Average responses from students working in the lab.

\begin{tabular}{|l|}
\hline \multicolumn{1}{|c|}{ Some Typical Comments } \\
\hline $\begin{array}{l}\text { Applying lean can save us a lot of time and energy on searching stuffs. But it did not } \\
\text { sustain long enough. Maybe we didn't work hard enough to keep it. }\end{array}$ \\
\hline $\begin{array}{l}\text { For the first few weeks the lab was cleaner and I could find all the tools I use on a regular } \\
\text { basis. After a while, most forget about LEAN and go back to their old ways and they it is } \\
\text { hard to find everything. We need to make sure all the students know about it and use it! }\end{array}$ \\
\hline $\begin{array}{l}\text { It improved the physical environment of lab somehow. One of the reasons why it is hard } \\
\text { to keep is because some of the regulations are not very practical for lab activities or are } \\
\text { kind of complication. }\end{array}$ \\
\hline $\begin{array}{l}\text { The activities in the lab should be standardized and it is also important that the operators } \\
\text { should follow the regulations. Maybe an inspector is necessary. }\end{array}$ \\
\hline
\end{tabular}

Table 2. Some typical comments from students working in the lab.

\section{Bibliography}

[1] Conner B. Gary and Gary Conner, Lean Manufacturing for the Small Shop, Society of Manufacturing Engineers, 2001.

[2] DVIRC, "Lean Manufacturing isn't Justfor the Plant...the Office CanCreate Just as Much Wastein Time and Manpower," Retrieved Feb 25, 2007, from http://www.dvirc.org/lean_office.pdf.

[3] Productivity Press Development Team, The Lean Office: Collected Practices and Cases, Productivity Press, 2005. 
[4] Don Tapping and Tom Shuker, Value Stream Management for the Lean Office, Productivity Press, 2002.

[5] Krista M. Schulte, Mohan R. Paruchuri and Jayesh B. Patel, "Applying Lean Principles in a Test Laboratory Environment, “ SAE 2005-01-1051, 2005 SAE World Congress, Detroit, Michigan.

[6] Smon Wood, "How LIMS Facilitates Lean ManufacturingProcesses in the Laboratory," Retrieved Feb 25, 2007 from http://www.starlims.com/AL-WoodReprint.pdf, American Laboratory September 2006.

\section{Biographical Sketch}

FRANK LIOU: Frank Liou is a Professor in the Mechanical Engineering Department at the University of Missouri-Rolla (UMR). He currently serves as the Director of the Manufacturing Engineering Program at UMR. His teaching and research interests include CAD/CAM, rapid prototyping, and rapid manufacturing. He has published over 100 technical papers and has research grants and contracts over $\$ 8 \mathrm{M}$. 